\title{
O Ensino de Laboratório de Física na Educação do Campo e da Cidade, considerando a estratégia do Teatro
}

\author{
Maíra Lorena Paixão Barbosa ${ }^{1}$; Milton Souza Ribeiro Miltão ${ }^{2}$ \\ 1. Bolsista PIBIC/CNPq-Af, Graduando em Física, Universidade Estadual de Feira de Santana, \\ e-mail:mairalorena12@hotmail.com \\ 2. Orientador, Departamento de Física, Universidade Estadual de Feira de Santana, e-mail: miltaaao@gmail.com
}

PALAVRAS-CHAVE: Instrumentação em Física, Educação do Campo, Educação da Cidade.

\section{INTRODUÇÃO}

Sabemos que a Física é a Ciência que estuda a natureza, buscando sempre compreender a origem, evolução e estrutura da matéria e radiação do Universo. A Física aparece aplicada em diferentes campos do conhecimento que, à primeira vista e em uma visão não filosófica, parecem completamente descorrelacionados. Como ciência, faz uso do método científico, nas suas ênfases teórica e experimental. Geralmente, seus conceitos e principalmente suas teorias e leis gerais (Mecânica Clássica, Eletromagnetismo, Termodinâmica, Mecânica Relativística, Mecânica Quântica, e Mecânica Estatística), são aplicados na vida do ser humano com o intuito de desenvolver a capacidade de percepção e aumentar o seu conhecimento. Essas seis teorias e leis gerais formam a base de sustentação do Campo do Saber da Física e, nesse sentido permitem explorar a natureza em suas várias nuances, desde os menores sistemas físicos, as partículas elementares, até o maior, o Universo.

Considerando o fato de que existem escolas do Campo para além da região de Feira de Santana, ampliamos o raio de ação de nosso plano de trabalho para outras regiões do Estado, haja vista a grande carência, no que tange aos conhecimentos físicos, dessas escolas existentes no Campo. Particularmente, participamos de uma atividade de campo na comunidade da Siribinha, com a ajuda da Associação Siribeira, onde interagimos com a comunidade, em especial, com uma representante dos professores bem como com a Assistente Social da Associação com o objetivo de compreendermos, no que tange as ciências físicas, como poderíamos contribuir no processo formativo da comunidade.

Com isso, levamos à comunidade dessas regiões uma ampla visão do conhecimento físico para possibilitar, através do diálogo sua construção. O objetivo principal, como estabelecido no plano de trabalho, é estudar o ensino de laboratório considerando a estratégia do Teatro, com o intuito de construir e estimular tal conhecimento na região do semiárido baiano, bem como naquelas onde a Educação do Campo se coloca, particularmente as de atuação da REFAISA (Rede das Escolas Famílias Agrícolas Integradas do Semi-Árido), da AECOFABA (Associação das Escolas das Comunidades e Famílias Agrícolas da Bahia) e da Siribeira (Associação Sócio Artístico Cultural e Ambiental do Conde). Essas regiões apresentam grande necessidade de desenvolvimento social e econômico, por serem áreas localizadas no interior do estado. Levando em conta o aspecto teatral didático-pedagógico, podemos entender que é aquele que deve despertar a curiosidade e o interesse que possibilite uma utilização informativa, formativa, recreativa, e educativa à assistência, possibilitando uma utilização crítica, estimulando o telespectador a dialogar com a cena ou imagem (teatral, que inclui a corporal, a áudio e a visual) para refazer a mensagem a partir da 
sua leitura, e cuja linguagem (da qual modalidade pertence ao gênero dramático, que conta com a participação de elementos extraverbais, como cenário, figurino, iluminação e sonoplastia) escolhida (tragédia, comédia, auto, farsa) de forma que melhor se adeque ao êxito de seu objetivo, enfatizando a subjetividade, a característica informativa, subvertendo e transgredindo as normas conservadoras (no que couber), buscando o contato entre emissor (atores) e receptor (público), facilitando a compreensão da mensagem ao usar o próprio código, e suscitando a ação ou reação da assistência, observando, também, a natureza inferencial da linguagem humana; levando em conta os seguintes critérios:

1. deve considerar os pré-requisitos;

2. deve ser rigoroso e claro em relação aos conceitos utilizados;

3. deve utilizar os elementos culturais da sociedade a que se destina.

\section{MATERIAL E MÉTODOS OU METODOLOGIA}

A metodologia utilizada neste plano de trabalho seguirá fazendo uma avaliação dos questionários e entrevistas aplicados durante as visitas a cada escola, em conjunto com uma revisão da bibliografia que dará suporte para a compreensão dos temas Instrumentação, Ensino de Laboratório, Filosofia da Física, e Etnofísica, a partir de textos clássicos que abordam o assunto; com isso poderemos utilizar materiais de baixo custo para a construção de experimentos em seguida com a peça teatral. Paralelamente a este processo, estaremos discutindo através de reuniões de estudo os problemas básicos enfrentados por essas escolas tanto na zona rural, quanto na urbana, com o intuito de garantir uma perfeita assimilação de tais conteúdos, analisando de que forma poderemos contribuir com uma construção sólida de alguns conhecimentos ligados à área de Física para possibilitar a utilização dos experimentos de baixo custo voltados para o conhecimento da Física.

\section{RESULTADOS E/OU DISCUSSÃO}

Como resultado temos: a Formação da candidata no tema da instrumentação cientifica, compreensão do significado de Pedagogia da Alternância, melhoria dos conhecimentos dos fenômenos físicos relacionados aos experimentos de baixo custo, construídos e apresentação de trabalhos em eventos tanto da área da física (ensino de física e instrumentação em física) quanto da área de educação. E a apresentação das peças teatrais pois trás o aspecto lúdico, além de proporcionar a participação do público, garantindo um diálogo direto.

\section{CONSIDERAÇÕES FINAIS}

Estudamos temas relacionados com a Instrumentação em Física, objetivando suas compreensões através da transposição didática, suas apresentações nas escolas do campo e da cidade, relacionando o teatro e assim o estudo de temas através de suas relações com o cotidiano, tanto na zona rural quanto na zona urbana. A vista disso, há uma compreensão do que é a Instrumentação em Física, que é a área da Física que lida 
com os aspectos experimentais, sem, no entanto, desconsiderar os aspectos teóricos, pois leva em conta que o ser humano, na sua construção do conhecimento, age através das ações do sentir, pensar e fazer. A peça teatral está sendo muito fundamental para esse crescimento, pois trás o aspecto lúdico, além de proporcionar a participação do público, garantindo um diálogo direto onde percebemos de forma clara os anseios e desejos da comunidade. Nesse sentido construímos experimentos de baixo custo, e levando o teatro como apoio, visando a compreensão do significado de Pedagogia da Alternância, a melhoria dos conhecimentos dos fenômenos físicos relacionados aos experimentos de baixo custo, construídos.

\section{REFERÊNCIAS}

ANACLETO, B. S. Etnofísica na lavoura de arroz. Dissertação de Mestrado. Programa de Pós-graduação em Ensino de Ciência e Matemática da Universidade Luterana do Brasil. 2007.

ARROYO, Miguel; CALDART, Roseli S.; MOLINA, Mônica Castagna (Org.). Por uma educação do campo. Petrópolis, RJ: Vozes, 2004.

BARBOSA, M.L.P.; MILTÃO, M.S.R. Alguns aspectos da Educação do Campo, Pedagogia da Alternância e Ciências Físicas nas EFAs do Semiárido. Anais do XXI Simpósio Nacional de Ensino de Física, 2015a.

BARBOSA, M.L.P.; MILTÃO, M.S.R. Educação do Campo, Pedagogia da Alternância e Ciências Físicas nas EFAs do Semiárido. Anais dos XXXII Encontro de Físicos do Norte e Nordeste 2014.

BARBOSA, M.L.P.; MILTÃO, M.S.R. O estudo da óptica e da fluorescência voltados para a Pedagogia da Alternância nas EFAs. Anais do XXX Encontro de Físicos do Norte e Nordeste. 2015b.

BARBOSA, M.L.P.; MILTÃO, M.S.R. O estudo da óptica e do telescópio voltado para a Pedagogia da Alternância nas EFAs. Anais dos XXI Encontro de Pesquisa Educacional do Norte e Nordeste. 2013.

CAVALCANTE, Ludmila Oliveira Holanda. A escola família agrícola - quais caminhos em que direção? In: Caderno Multidisciplinar - Educação e Contexto do Semi-Árido. Rede de Educação do Semi-árido. Juazeiro, Bahia. 2006.

DEMO, Pedro. Pesquisa Participante - saber pensar e intervir juntos. Série Pesquisa em Educação. Brasília, DF. Liber Livro Editora LTDA.2004.

FREIRE, Paulo. Pedagogia do Oprimido. $17^{\circ}$ Ed. Rio de Janeiro; Paz e Terra, 1987;

GIANOTTEN Vera e WIT, Ton de. Pesquisa Participante em um contexto de economia camponesa. In: Repensando a Pesquisa Participante. BRANDÃO, C. R. (Org.). São Paulo. Editora Brasiliense. 2000.

GUERRA, Andreia; REIS, Jose Claudio; BRAGA, Marco. Uma Abordagem HistóricoFilosófica para o Eletromagnetismo no Ensino Médio. Cad. Bras. Ens. Fís., v. 21, n. 2: p. 224-248, ago. 2004.

KLEIBER, J. Compêndio de Física, 2a ed. Globo, Porto Alegre - RGS, 1935.

LOPES, J Bernardino. Aprender e Ensinar Física. Lisboa. Fundação Calouste Gulbenkian, 2004.

MASSARANI, LUISA. Divulgação científica: considerações sobre o presente momento. Com Ciência, no 100, julho 2008. 
MILTÃO, M. S. R.; SANTANA, C. S. C.; BARRETO, A. L. V.; CARDOSO, G. K. R. O Ensino de Física e a Educação do Campo: uma relação que precisa ser efetivada. In: Álvaro Santos Alves; José Carlos Oliveira de Jesus; Gustavo Rodrigues Rocha. (Org.). Ensino de Física: reflexões, abordagens e práticas. 1ed. São Paulo: Livraria da Física, 2012, v. 1, p. 169-198.

MILTÃO, M. S. R.; SIMÕES, Maria Tereza Moraes; SERRA, Denise Simões; SOUSA, Tânia Cristina R. Considerações Gerais sobre o Uso dos Livros Didáticos a partir da Experiência de Professores em Sala de Aula no Nível Médio. Caderno de Física da UEFS, v. 04, p. 51-80, 2006.

MILTÃO, M. S. R.; SIMÕES, Maria Tereza Moraes; SERRA, Denise Simões; SOUSA, Tânia Cristina R. O Uso do Livro Didático na Visão dos Professores da Escola Secundária: considerações gerais. Sitientibus Série Ciências Físicas, v. 02, p. 68-84, 2006.

MILTÃO, M. S. R.; FREITAS, D. S.; MOTTA, Durval Eusíquio de Miranda. O ensino de laboratório de física na UEFS: considerações teórico-pedagógicas. Sitientibus (UEFS), Feira de Santana, v. 16, p. 123-130, 1997.

MILTÃO, M. S. R.; FREITAS, D. S.; MOTTA, Durval Eusíquio de Miranda. A problemática do ensino de laboratório de física na UEFS. Revista Brasileira de Ensino de Física, v. 19, p. 444-447, 1997.

PAIVA, Vanilda. História da Educação popular no Brasil: educação popular e educação de adultos. 6. ed. São Paulo: Loyola, 2003.

PENA, Fábio Luís Alves; RIBEIRO FILHO, Aurino. Obstáculos para o uso da experimentação no ensino de Física: um estudo a partir de relatos de experiências pedagógicas brasileiras publicados em periódicos nacionais da área (1971-2006). Revista Brasileira de Pesquisa em Educação em Ciências, Vol. 9 No 1, p. 1-13, 2009.

SANTOS, Renato P. dos. A Parábola no Oriente: Etnofísica, Psicogénese e Multiculturalidade. In: Atas do 10 Colóquio Intercultural - “A Comunicação entre Culturas", Almada, Portugal: ADECI - Associação Portuguesa para a formação e a Investigação em Comunicação Intercultural, 2002. 